\title{
Phagocytosis of PLGA Microparticles in Rat Peritoneal Exudate Cells: A Time-Dependent Study
}

\author{
Anderson de Jesus Gomes, ${ }^{1, \star}$ Claure Nain Lunardi, ${ }^{2}$ Flávio Henrique Caetano, ${ }^{3}$ \\ Laurelúcia Orive Lunardi, ${ }^{3}$ and Antonio Eduardo da Hora Machado ${ }^{1}$ \\ ${ }^{1}$ Laboratório de Fotoquímica, Instituto de Química, Universidade Federal de Uberlândia, P.O. Box 593, CEP 38400-089 \\ Uberlândia, $M G$, Brazil \\ ${ }^{2}$ Laboratório de Farmacologia, Faculdade de Ciências Farmacêuticas de Ribeirão Preto-USP, Av. Café s/n CEP 14040-903 \\ Ribeirão Preto, SP, Brazil \\ ${ }^{3}$ Instituto de Biociências, Universidade Estadual Júlio de Mesquita Filho, Av: 24 N1515 CEP 13506-900 Rio Claro, SP, Brazil
}

\begin{abstract}
With the purpose of enhancing the efficacy of microparticle-encapsulated therapeutic agents, in this study we evaluated the phagocytic ability of rat peritoneal exudate cells and the preferential location of poly(D,L-lactide-co-glycolic acid) (PLGA) microparticles inside these cells. The microparticles used were produced by a solvent evaporation method and were characterized by dynamic light scattering (DLS), transmission electron microscopy (TEM), and scanning electron microscopy (SEM). Size distribution analysis using DLS and SEM showed that the particles were spherical, with diameters falling between 0.5 and $1.5 \mu \mathrm{m}$. Results from cell adhesion by SEM assay, indicated that the PLGA microparticles are not toxic to cells and do not cause any distinct damage to them as confirmed by the MTT (3-(4,5-dimethylthiazol-2-yl)-2,5-diphenyl tetrazolium bromide) assay. Among the large variety of cell populations found in the peritoneal exudates (neutrophils, eosinophils, monocytes, and macrophages), TEM showed that only the latter phagocytosed PLGA microparticles, in a time-dependent manner. The results obtained indicate that the microparticles studied show merits as possible carriers of drugs for intracellular delivery.
\end{abstract}

Key words: microparticles, drug delivery, peritoneal exudate cells, macrophage, TEM, SEM

\section{INTRODUCTION}

In recent years, special interest has been focused on the development of drug delivery systems (DDS), prepared from polyester poly(D,L-lactide-co-glycolic acid) (PLGA) (Jain, 2000; Tunçay et al., 2000; Fu et al., 2002; Konan et al., 2003; Panyam \& Labhasetwar, 2003; Panyam et al., 2003; Kumar et al., 2004). The synthetic biodegradable system used in this study consisted of PLGA microparticles, which have gained considerable interest due to properties like lack of antigenic action and the capacity to encapsulate both hydrophilic or lipophilic drugs (Kumar et al., 2004). This DDS has been investigated not only in the light of its controlled drug-releasing capacity, but also for its ability to reach its target cells, decreasing undesirable side effects and increasing the therapeutic ones (Okada \& Toguchi, 1995). Aliphatic polyesters such as polylactide and its copolymers with glycolic acid have received considerable interest because they are biodegradable and biocompatible synthetic polymers that degrade to lactic $\left(\mathrm{C}_{3} \mathrm{H}_{6} \mathrm{O}_{3}\right)$ and glycolic $\left(\mathrm{C}_{2} \mathrm{H}_{4} \mathrm{O}_{3}\right)$

Received August 2, 2005; accepted January 6, 2006.

*Corresponding author. E-mail: anderson@iqufu.ufu.br acids. Such polymers become degraded in vivo by hydrolysis of their ester linkages, a process that is acid, base, or enzyme catalyzed. Their breakdown products, $\mathrm{CO}_{2}$ and $\mathrm{H}_{2} \mathrm{O}$, are easily eliminated (Dunne et al., 2000). These microparticles could offer a number of advantages over other delivery systems because: (a) they maintain their chemicophysical characteristics unaltered for long time periods, allowing extended storage; (b) depending on their composition, they can be administered through different modes of delivery (oral, intramuscular, or subcutaneous); and (c) they are suitable for industrial production (Lemoine et al., 1998; Esposito et al., 1999). Aiming at a number of applications, it is important to study the kinetics of cellular and tissue uptake, intracellular distribution and retention, and in vivo biodistribution of these microparticles (Panyam \& Labhasetwar, 2003). For example, to optimize drug therapy, it might be required to study the efficiency of particle localization in a particular cell population, organ, or specific tissue following local or systemic administration (Lamprecht et al., 2001). Similarly, it is necessary to study the effect of various microparticle formulation parameters and their physical properties (e.g., surface charge, particle size) on their uptake and distribution within various cellular compartments (e.g., endo-lysosomes, cytoplasm, nucleus, etc.). Understanding 
the intracellular and tissue distribution of microparticles is also useful to elucidate the mechanism of enhanced therapeutic efficacy of particle-encapsulated therapeutic agents (Panyam et al., 2003). In this study we describe the internalization process of PLGA microparticles by rat peritoneal exudate cells in the absence of any opsonization processes.

\section{Material and Methods}

\section{Materials}

PLGA (50:50, Mw $17 \mathrm{kDa}$ ) and 3-(4,5-dimethylthiazol-2-yl)2,5-diphenyl tetrazolium bromide (MTT) were obtained from Sigma Chemical, Inc. (St. Louis, MO), Polyvinyl alcohol (PVA) (13-23 kDa, 87-89\% hydrolyzed) was supplied by Aldrich (Milwaukee, WI). Analytical grade dichloromethane was supplied by Merck (Darmstadt, Germany). All other chemicals were of analytical grade and were used without further purification.

\section{Preparation of Polymeric Microparticles}

Microparticles (MP) were produced by the solvent evaporation procedure described by Gomes et al. (2005). Typically, the organic phase consisted of $0.1 \mathrm{~g}$ of 50:50 PLGA polymer, dissolved in $10 \mathrm{ml}$ of dichloromethane. It was dropped into an aqueous homogeneous phase $(100 \mathrm{ml}$ of an aqueous phase containing $3 \%[\mathrm{w} / \mathrm{v}]$ of $88 \%$ hydrolyzed PVA as dispersing agent), under ice cooling, and with stirring at 13,500 rpm, during $3 \mathrm{~min}$. Solvent evaporation was then carried out by gentle magnetic stirring at room temperature, usually for 3-5 h. Microparticles were recovered by centrifugation at $4^{\circ} \mathrm{C}$ for $5 \mathrm{~min}$ at $10,000 \mathrm{rpm}$, washed three times with distilled water at $10^{\circ} \mathrm{C}$, and lyophilized.

\section{Morphology of Microparticles: SEM Analysis}

SEM was used to evaluate the shape and size of PLGA microparticles. Samples were washed with sterile distilled water, fixed in $2.5 \%$ (v:v) glutaraldehyde in water, for $2 \mathrm{~h}$, again washed with water, dehydrated in a graded ethanol series, and critically point dried. Samples containing microparticles were mounted on aluminum stubs and, because of their lack of electrical conductivity, coated with $50 \mathrm{~nm}$ gold coating under an argon atmosphere. Microparticle diameters were measured using a ruler and their mean value found using the scale on the SEM. A Electronscan (Philips ESEM 2020) operating at $5 \mathrm{kV}$ was used for these measurements in the traditional mode (SE detector).

\section{Particle Size and Surface Charge (Zeta Potential)}

Surface charge and size of the microparticles were determined by photon correlation spectroscopy, using quasielastic light scattering equipment (Zetasizer 3000; Malvern Instrument, Worcestershire, UK, with a 10-mW He-Ne laser beam at $633 \mathrm{~nm}$ wavelength and $25^{\circ} \mathrm{C}$ and a scattering angle of $\left.90^{\circ}\right)$. A dilute suspension $(1.0 \mathrm{mg} / \mathrm{ml})$ of microparticles was prepared in doubly distilled water and sonicated in an ice bath for $30 \mathrm{~s}$ and subjected to particle size analysis. Zeta potential of microparticles in $0.1 \mathrm{mM}$ Hank's buffer, $\mathrm{pH} 7.4$ $(1.0 \mathrm{mg} / \mathrm{ml})$, was determined using ZetaPlus ${ }^{\mathrm{TM}}$ in the zeta potential analysis mode.

\section{Residual PVA Content}

The residual amount of PVA associated with microparticles was determined by a colorimetric method (Sahoo et al., 2002). A calibration curve was prepared by dissolving PVA $\left(2-10 \mathrm{mg}\right.$ ) in $2 \mathrm{ml}$ of $0.5 \mathrm{M} \mathrm{NaOH}$ for $15 \mathrm{~min}$ at $60^{\circ} \mathrm{C}$. Samples were then neutralized with $900 \mu \mathrm{L}$ of $1 \mathrm{M} \mathrm{HCl}$ and their volumes adjusted to $5 \mathrm{ml}$ with distilled water. To each sample, $3 \mathrm{ml}$ of a $0.65 \mathrm{M}$ solution of boric acid, $0.5 \mathrm{ml}$ of $\mathrm{I}_{2} / \mathrm{KI}(0.05 / 0.15 \mathrm{M})$ solution, and $1.5 \mathrm{ml}$ of distilled water were added. Finally, the visible spectra absorbance of the samples was measured at $690 \mathrm{~nm}$ (UV-1601PC UV-Vis Spectrophotometer, Shimadzu Scientific Instruments) after 15 min incubation (Figure 4, below). The lyophilized PLGA microparticles $(2 \mathrm{mg})$ were solubilized in the same way to determine the residual PVA content. The values of absorbance of PVA obtained after microparticle dissolution was used to determine the concentration of residual PVA. This procedure was performed in triplicate.

\section{MTT Assay}

Cell viability was measured using a spectrophotometric MTT assay. To cells preincubated with microparticles of PLGA $(0-1 \mathrm{mg} / \mathrm{ml})$ for $2 \mathrm{~h}$ was added a MTT solution (150 $\mu \mathrm{l}$ per well), containing $4 \mathrm{mg}$ per $\mathrm{ml}$ of the MTT reagent. The 24 well-containing plates used were incubated for $3 \mathrm{~h}$ at $37^{\circ} \mathrm{C}$ in a $\mathrm{CO}_{2}$ incubator. The cells were then solubilized with an organic solvent (isopropanol) and the released solubilized formazen reagent measured spectrophotometrically. The absorbance at $570 \mathrm{~nm}$ was measured with a UV-1201 Shimadzu spectrophotometer and the percentage of vital cells calculated in relation to control cells incubated in the absence of microparticles.

\section{Microparticles in Rat Peritoneal Exudate Cells: TEM Analysis}

Time dependency studies were performed to evaluate the phagocyte ability of the peritoneal exudate cells from male Wistar rats weighing on an average $150.0 \mathrm{~g}(n=6)$. Animals were anesthetized using a mixture of halothane, $\mathrm{N}_{2} \mathrm{O}$, and $\mathrm{O}_{2}$, according to National Institutes of Health guidelines for the care and use of laboratory animals (NIH publication 85-23 Rev. 1985). After shaving and disinfection, $20 \mathrm{ml}$ of PBS buffer were injected intraperitonealy into each rat; following a 5-min abdominal massage to free adherent macrophages, the PBS cell suspension was withdrawn with a syringe through a small incision made in the abdominal 

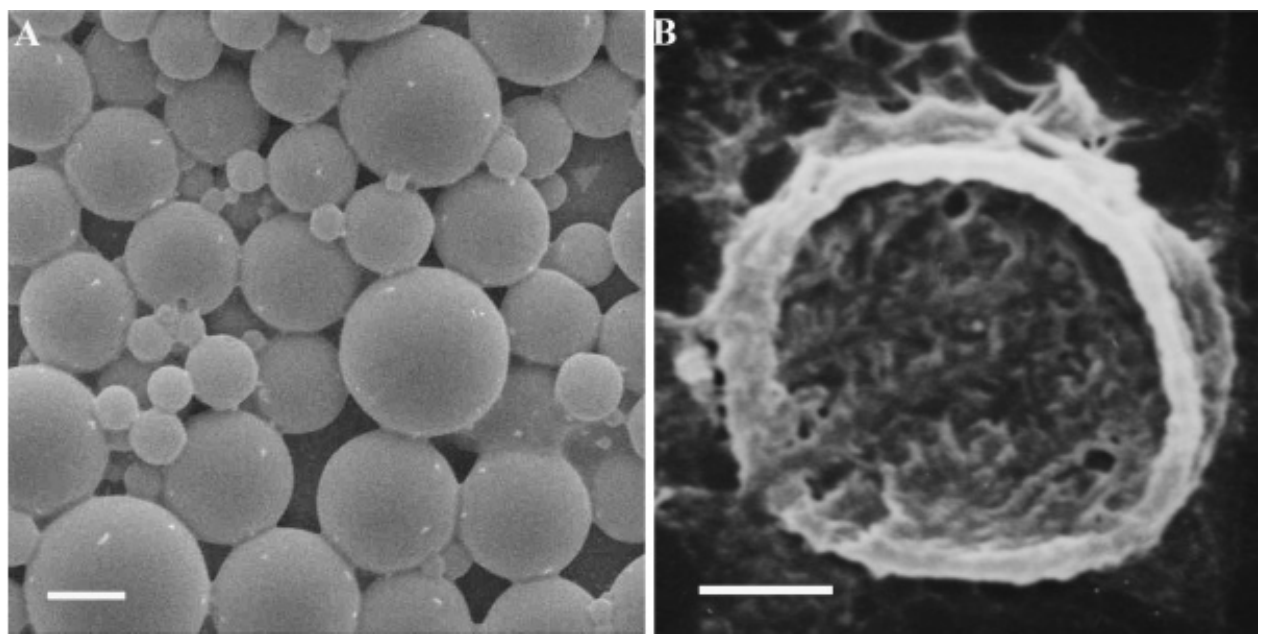

Figure 1. A: Morphology of the external surface of microparticles prepared by the solvent evaporation method. B: Idem of the inner surface after microparticle cross section. Magnification $15,000 \times$ and $50,000 \times$ by SEM. Bar $=0.1 \mu \mathrm{m}$ and $0.5 \mu \mathrm{m}$.

wall. The peritoneal lavage fluid was centrifuged at $400 \times \mathrm{g}$ for $10 \mathrm{~min}$ and the cell pellet resuspended in PBS buffer and divided into four aliquots of $2 \mathrm{ml}$ each. Time-dependent assays were done incubating samples with PLGA microparticles $(300 \mu \mathrm{g} / \mathrm{ml})$ for 15,30 , and $120 \mathrm{~min}$, respectively. Negative controls were incubated for $120 \mathrm{~min}$, without microparticles. Following incubation, cells were washed twice with PBS solution. Possible untoward effects of fixative agents, such as $3.0 \%$ glutaraldehyde in $0.1 \mathrm{M}$ sodium phosphate buffer ( $\mathrm{pH} 7.4$ ), 2.5\% glutaraldehyde in $0.1 \mathrm{M}$ synn collidine buffer ( $\mathrm{pH} 7.4$ ), and $2.5 \%$ glutaraldehyde in $0.1 \mathrm{M}$ sodium cacodylate buffer $(\mathrm{pH} 7.4)$ for $2 \mathrm{~h}$ at $25^{\circ} \mathrm{C}$ each, were evaluated in this study.

For TEM studies the samples were fixed in $2.5 \%$ glutaraldehyde in $0.1 \mathrm{M}$ sodium cacodylate buffer ( $\mathrm{pH} 7.4)$ for $2 \mathrm{~h}$ at $25^{\circ} \mathrm{C}$. Fixed cells were then postfixed in $1 \%$ osmium tetroxide in the same buffer for $1 \mathrm{~h}$, dehydrated in a graded acetone series, and embedded in epoxy resin (Embed 812, Electron Microscopy Sciences, Hatfield, PA). Ultrathin sections were contrasted with alcoholic $2 \%$ uranyl acetate and $5 \%$ lead citrate. Ultrastructural examination was performed under a transmission electron microscope (Philips CM 100).

\section{Results AND Discussion}

\section{Microparticle Morphology}

The morphology and size of the MP were determined by SEM. MP produced by solvent evaporation were spherical and possessed a smooth external surface (Fig. 1A). Figure $1 \mathrm{~B}$ shows the inner surface of a cross-sectioned PLGA microparticle, demonstrating it to be a microcapsule (Ahsan et al., 2002).

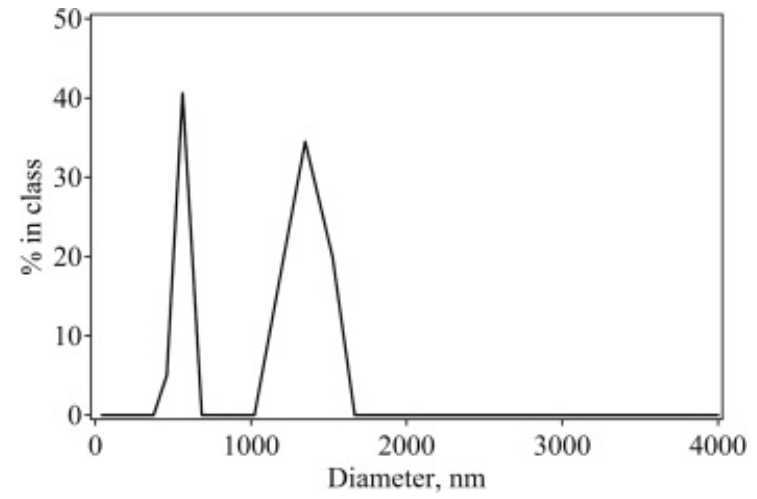

Figure 2. Size distribution of PLGA microparticles by dynamic light scattering.

\section{Particle Size and Surface Charge (Zeta Potential)}

Dynamic light scattering (DLS), demonstrated the MP analyzed to present a bimodal size distribution, their mean particle size varying between 0.5 and $1.5 \mu \mathrm{m}$ (Fig. 2). Recent studies with nanoparticles in the biomedical and biotechnological areas showed their particle size to range between 10 and $1000 \mathrm{~nm}$, acceptable for intravenous injection (Kreuter, 2004). The inconvenience of administering particles with a diameter of up to $4 \mu \mathrm{m}$ seems to be their inefficiency as a DDS, because of possible accumulation in the lung capillaries and removal by the reticulo endothelial system (Jeon et al., 2000). Our modification of the solvent evaporation technique renders it possible to prepare smaller particles of $<2.0 \mu \mathrm{m}$, useful as a DDS.

Colloidal stability was analyzed by measuring the zeta potential of the microparticles (Fig. 3). PLGA particles were 


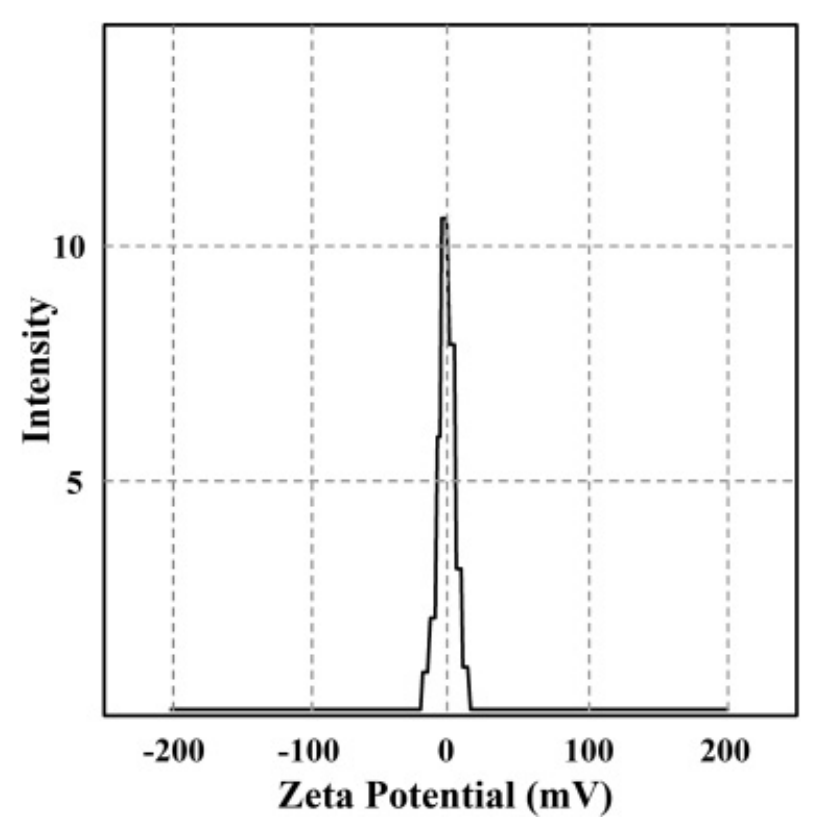

Figure 3. Zeta potential of PLGA microparticle's surface.

negatively charged (-3.2 $\mathrm{mV}$ at $\mathrm{pH} 7.4)$, a value normally considered to be associated with a stable colloid nature (Ruan \& Feng, 2003). The negative zeta potential can be explained by residual PVA still present on the particle's surface even after three washings and which affects the number of carboxylate group endings (Lacasse et al., 1998; Kumar et al., 2004).

\section{Residual PVA Content}

The percentage of residual PVA was in the range of $1.6 \%-$ $3.4 \%(w / w)$ (Fig. 4). According to Sahoo et al. (2002), the fraction of PVA that remains associated with the surface of the particles affects their physical and cellular uptake properties. Particle hydrophobicity decreases with the amount of associated PVA reducing their cellular uptake (Sahoo et al., 2002). In our work, PLGA microparticles were washed three times with PBS buffer to remove the excess PVA, resulting in improved particle recognition by macrophages.

\section{Incubation Process of MP with Peritoneal Exudates Cells}

Following incubation of MP with peritoneal exudate cells for 15,30 , and $120 \mathrm{~min}$, respectively, the efficiency of phagocytosis (adhesion or phagocytosis) was evaluated by SEM. Figure 5A shows a control cell (without MP), Figure $5 \mathrm{~B}$ a cell incubated with MP at zero time, and Figure 5C peritoneal exudate cells incubated with MP for $30 \mathrm{~min}$. After this period, particles had already adhered to the cell surface. Figure 5D shows that after $120 \mathrm{~min}$, the particles had been completely phagocytized by the cells, appearing as extensions of the cell surface. This result furnished the

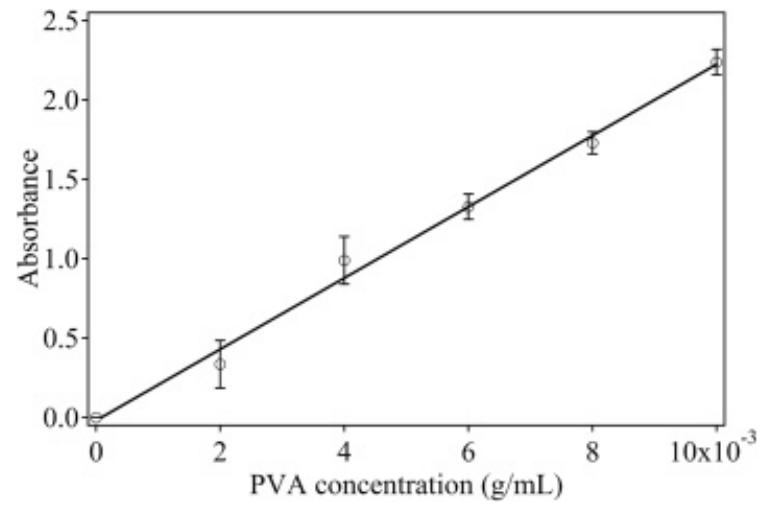

Figure 4. Calibration curve used to determine residual content of PVA on PLGA microparticles.

minimum time period required for a large majority of the MP to be engulfed by phagocytosis by the peritoneal fluid exudate cells.

\section{MTT Assay}

Microparticle toxicity to peritoneal exudate cells was investigated by exposing macrophages to increasing amounts of the microparticles. Viability evaluated by the MTT test was not affected in macrophages exposed to 0.1 to $1.0 \mathrm{mg} / \mathrm{ml}$ of MP, respectively (Fig. 6; Artursson et al., 1987). This indicates that the PLGA microparticles were not toxic to the cells and could be used as a DDS.

\section{Microparticles in Rat Peritoneal Exudates Cells: TEM Analysis}

Biocompatibility studies using microspheres in vitro generally employ a cell culture model (Panyam et al., 2003). In the present work we used peritoneal exudate cells from live male Wistar rats. Ultrastructural examination was performed by TEM (Fig. 7A, control). The experiments demonstrated that microparticles entered macrophages through an apparently conventional form of phagocytosis, in which phagocyte pseudopods moved circumferentially around the microparticles until fusing at their distal tips. Microsphere contour boundaries were clearly observed without the need for any specific electron-dense marker (Fig. 7B,D, arrow).

Our results indicate that in a time-dependent manner, following $15 \mathrm{~min}$ of incubation phagocytosis begins (Fig. 7B), followed by internalization of the particles for $30 \mathrm{~min}$ (Fig. 7C). After 120 min, PLGA microparticles of different sizes were located inside the macrophages (Fig. 7D). The experiment also demonstrated that almost all MP were phagocytosed within $120 \mathrm{~min}$. We believe that the TEM technique is more sensitive for assessing newly ingested microparticles, because obviously, the number of microparticles phagocytosed per macrophage increases with incu- 

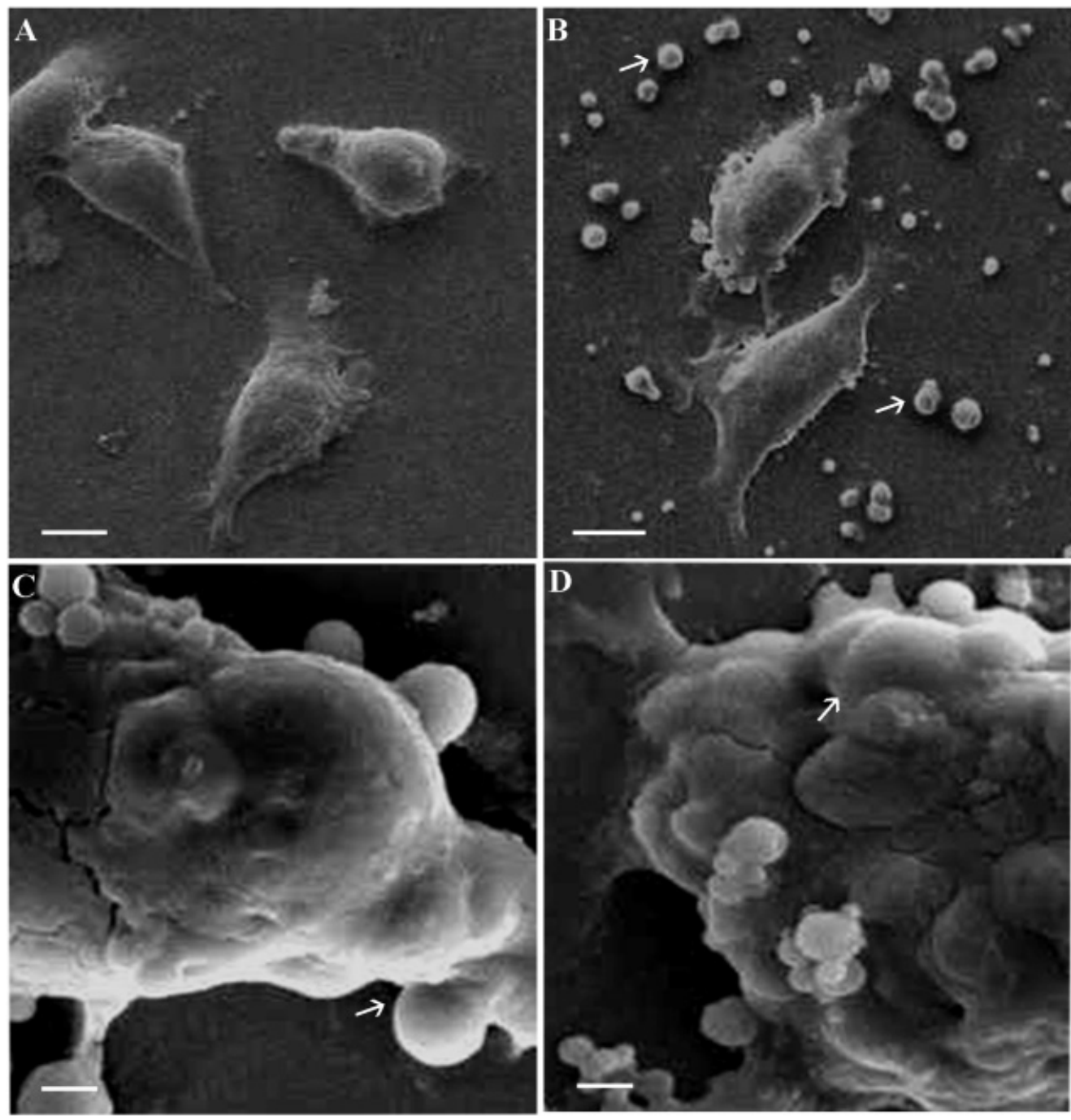

Figure 5. Scanning electron micrograph of macrophages exposed to microparticles (arrow). A: Control cell (without MP); B: Cell incubated with MP at zero time; C: Peritoneal exudate cells incubated with MP for 30 minutes; D: Cell incubated with MP for two hours of incubation. Bar $=1.3 \mu \mathrm{m}$.

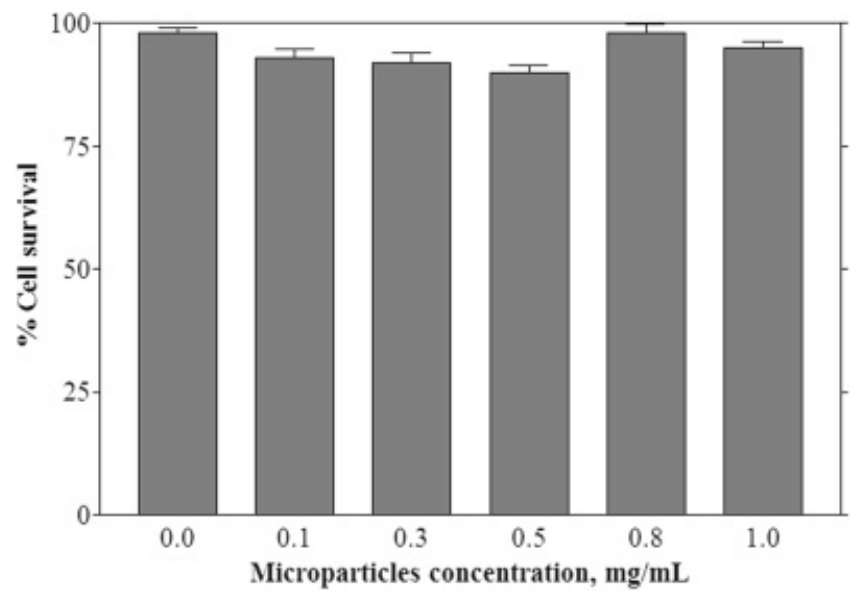

Figure 6. Effect of PLGA microparticles on cells of rat peritoneal fluid exudate measured by a MTT assay. bation time. It has been demonstrated that particle uptake by phagocytic cells is largely affected by the size and surface properties of the particles (Tabata \& Ikada, 1988; Moghimi et al., 2001; Ahsan et al., 2002).

The external surface of PLGA microparticles possesses hydroxyl groups of PVA molecules attached to PLGA acetyl groups via hydrophobic links (Murakami et al., 1999). The reaction of PVA cross-linked by glutaraldehyde was observed by treating a PVA membrane surface with a specified amount of a dialdehyde such as glutaraldehyde (Castelli et al., 2000). Among the four fixative solutions used here, the best results for the preservation of the microparticles were the use of the combination of glutaraldehyde with cacodylate buffer ( $\mathrm{pH}=7.4)$, as illustrated in Figure 7. The use of glutaraldehyde in this buffer instead of the PBS buffer offers a greater advantage due to the reduction of polymerization of glutaraldehyde with an increase of its 

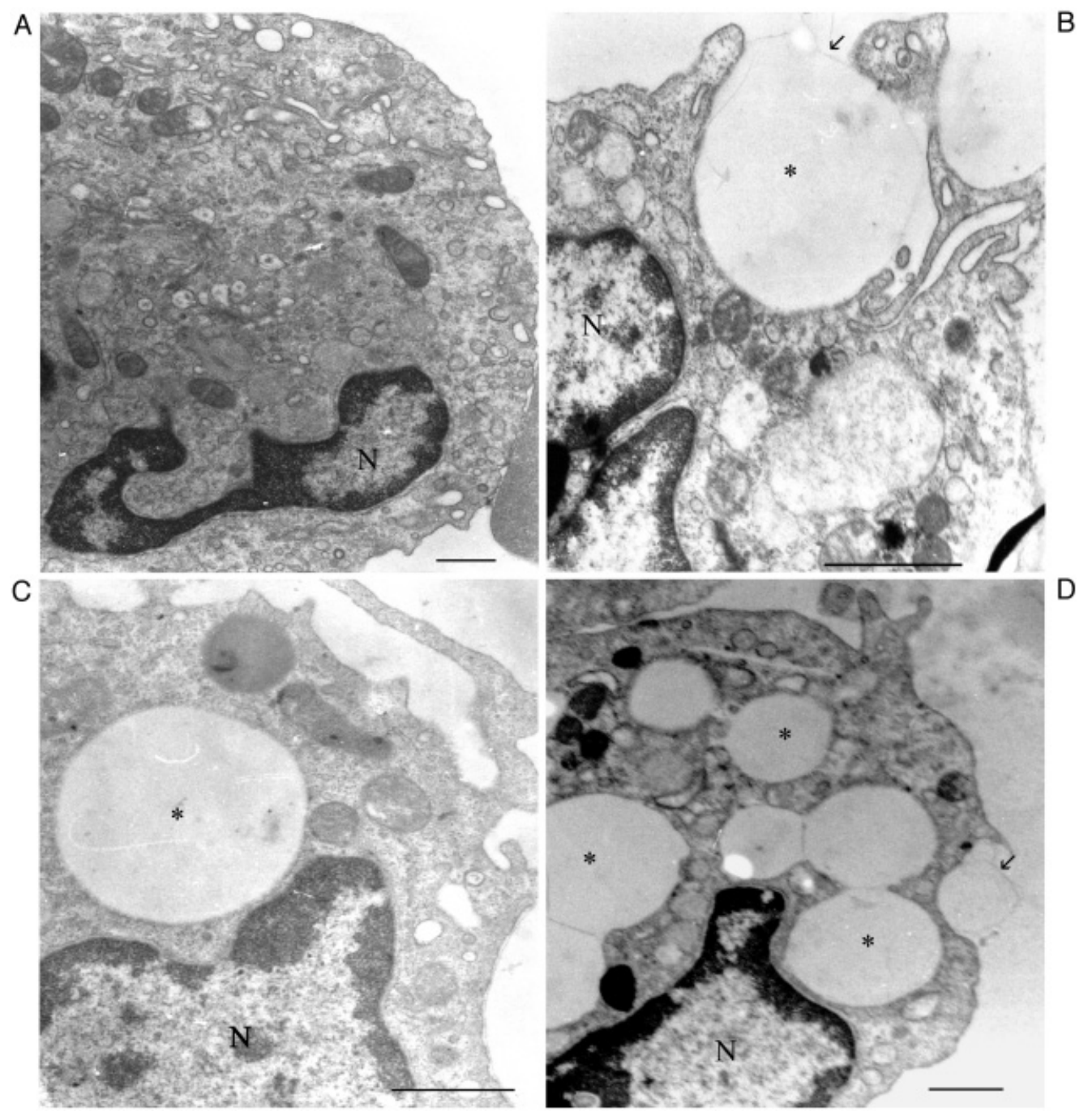

Figure 7. A: Exudate macrophage cell without microparticles (control). N: nucleus. B: PLGA microparticles (indicated by asterisks) interacting with the cell membrane in the process of phagocytosis after 15 min of incubation. C: Internalization of PLGA microparticles. Phagosome after $30 \mathrm{~min}$ of incubation. D: Heterogeneous population of PLGA microparticles (asterisks) phagocytosed by macrophages after $120 \mathrm{~min}$ of incubation. Bars $=0.5 \mu \mathrm{m}$.

fixative activity (Hayat, 1981). This feature enhanced the visualization of the microparticles by TEM.

\section{CONCLUSION}

Our studies showed good preservation of PLGA microparticles, achieved by the use of a combination of glutaraldehyde and cacodylate buffer. They demonstrate that the uptake of the microparticles by peritoneal exudate phagocytic cells exhibits a time dependence for particle attachment and internalization, and that this process was observed only for macrophage cells.

\section{ACKNOWLEDGMENTS}

This study was partly supported by CNPq and FAPEMIG Grants (303911/03-4; 302679/2002-2 and 474468/2003-8). The author thanks Monika Iamondi and Antonio Teruyoshi Yabuky of the Laboratory of Electronic Microscopy, ICB, UNESP, Rio Claro, SP, Brazil for technical assistance.

\section{REFERENCES}

Ahsan, F., Rivas, I.P., Khan, M.A. \& Suárez, A.I.T. (2002). Targeting to macrophage: Role of physicochemical properties 
of particulate carriers-lipossomes and microsperes-on the phagocytosis by macrophages. J Contr Release 79, 29-40.

Artursson, P., Arro, E., Edman, P., Ericsson, J.L.E. \& SJöholm, I. (1987). Biodegradable microsphere V: Stimulation of macrophages with microparticles made of various polysaccharides. $J$ Pharm Sci 76, 127-133.

Castelli, F., Pitarresi, G. \& Giammona, G. (2000). Influence of different parameters on drug release from hydrogel systems to a biomembrane model. Evaluation by differential scanning calorimetry technique. Biomaterials 21, 821-833.

Dunne, M., Corrigan, O.I. \& Ramtoola, Z. (2000). Influence of particle size and dissolution conditions on the degradation properties of polylactide-co-glycolide particles. Biomaterials 21, 1659-1668.

Esposito, E., Sebben, S., Cortesi, R., Menegatti, E. \& NasTRUZZI, C. (1999). Preparation and characterization of cationic microspheres for gene delivery. Int J Pharm 189, 29-41.

Fu, F., LI, X. \& Wu, C. (2002). Encapsulation of phthalocyanines in biodegradable poly(sebacic anhydride) nanoparticles. Langmuir 18, 3843-3847.

Gomes, A.J., Lunardi, L.O., Marchetti, J.M., Lunardi, C.N. \& Tedesco, A.C. (2005). Photobiological and ultrastructural studies of nanoparticle of poly(lactic-co-glycolic acid)-containing bacteriochlorophyll- $a$ as a photosensitizer useful for PDT treatment. Drug Deliv 12, 1-6.

Hayat, M.A. (1981). Fixation for Electron Microscopy. London: Academic Press Inc.

JAIN, R.A. (2000). The manufacturing techniques of various drug loaded biodegradable poly(lactide-co-glycolide) (PLGA) devices. Biomaterials 21, 2475-2490.

Jeon, H.-J., Jeong, Y.-I., Jang, M.-K., PARK, Y.-H. \& NAH, J.-W. (2000). Effect of solvent on the preparation of surfactant-free poly(DL-lactide-co-glycolide) nanoparticles and norfloxacin release characteristics. Int J Pharm 207, 99-108.

Konan, Y.N., Chevallier, J., Gurny, R. \& Allémann, E. (2003). Encapsulation of p-THPP into nanoparticles: Cellular uptake, subcellular localization and effect of serum on the photodynamic activity. Photochem Photobiol 77, 638-644.

Kreuter, J. (2004). Influence of the surface properties on nanoparticle-mediated transport of drugs to the brain. J Nanosci Nanotechnol 4, 484-488.

Kumar, M.N.V.R., Bakowsky, U. \& Lehr, C.M. (2004). Preparation and characterization of cationic PLGA nanospheres as DNA carriers. Biomaterials 25, 1771-1777.
Lacasse, F.X., Fillion, M.C., Phillips, N.C., Escher, E., McMullen, J.N. \& Hildgen, P. (1998). Influence of surface properties at biodegradable microsphere surfaces: Effects on plasma protein adsorption and phagocytosis. Pharm Res 15, 312-317.

LAmprecht, A., Schäfer, U. \& Lehr, C.-M. (2001). Size-dependent bioadhesion of micro- and nanoparticulate carriers to the inflamed colonic mucosa. Pharm Res 18, 788-793.

Lemoine, D., Wauters, F., Bouchend'homme, S. \& Preat, V. (1998). Preparation and characterization of alginate microspheres containing a model antigen. Int J Pharm 176, 9-19.

Moghimi, S.M., Hunter, A.C. \& Murray, J.C. (2001). Longcirculating and target specific microparticles: Theory to practice. Pharmacol Rev 53, 283-318.

Murakami, H., Кobayashi, M., Kamada, M., Takeuchi, H. \& Kawashima, Y. (1999). Preparation of poly(DL-lactide-coglycolide) nanoparticles by modified spontaneous emulsification solvent diffusion method. Int J Pharm 187, 143-149.

Okada, H. \& Toguchi, H. (1995). Biodegradable microspheres in drug delivery. Crit Rev Ther Drug Carrier Syst 12, 1-99.

Panyam, J. \& Labhasetwar, V. (2003). Biodegradable nanoparticles for drug and gene delivery to cells and tissue. Adv Drug Deliv Rev 55, 329-347.

Panyam, J., Sahoo, S.K., Prabha, S., Bargar, T. \& Labhasetwar, V. (2003). Fluorescence and electron microscopy probes for cellular and tissue uptake of poly(D,L-lactide-co-glycolide) nanoparticles. Int J Pharm 262, 1-11.

Ruan, G. \& Feng, S.-S. (2003). Preparation and characterization of poly(lactic acid)-poly(ethyleneglycol)-poly(lactic acid) (PLAPEG-PLA) microspheres for controlled release of paclitaxel. Biomaterials 24, 5037-5044.

Sahoo, S.K., Panyam, J., Prabha, S. \& Labhasetwar, V. (2002). Residual polyvinyl alcohol associated with poly (D,L-lactide-cogly-colide) nanoparticles affects their physical properties and cellular uptake. J Control Release 82, 105-114.

Taвata, Y. \& Ikada, Y. (1988). Effect on the size and surface charge of polymer microspheres on their phagocytosis by macrophage. Biomaterials 9, 356-362.

Tunçay, M., Çalis, S., Kas, H.S., Ercan, M.T., Peksoy, I. \& Hincal, A.A. (2000). Diclofenac sodium incorporated PLGA (50:50) microspheres: Formulation considerations and in vitro:in vivo evaluation. Int J Pharm 195, 179-188. 